\title{
Why are both UGC- CARE List of Journals and Good Academic Research Practices (GARP) Archaic?
}

\author{
Vasantha Raju N¹. \& N.S. Harinarayana ${ }^{2}$ \\ ${ }^{1}$ Librarian, Government First Grade College, Talakadu-571 122 \\ vasanthrz@gmail.com \\ ORCID ID: 0000-0003-3594-6018 (Corresponding Author) \\ Professor, Department of Studies in Library \& Information Science \\ University of Mysore, Mysore-570006 \\ harinarayana@lisc.uni-mysore.ac.in \\ ORCID ID: 0000-0002-0359-8023
}

\begin{abstract}
:
This paper discusses the limitations of Good Academic Research Practices (GARP) and UGCCARE List in engaging with the emerging scholarly open publishing platforms, specifically preprints. This paper throws some light on preprints and their role in accelerating science communication during the COVID-19 pandemic. The UGC's opaqueness towards emerging open publishing platforms in its GARP document and propagating traditional scholarly publications through UGC-CARE List has also been deliberated.
\end{abstract}

\section{KEYWORDS:}

University Grants Commission (UGC), UGC-CARE List, Good Academic Research Practices (GARP), Scholarly

Publishing, Scholarly Communication, Open Publishing Models, Preprints, Open Access, India 


\section{INTRODUCTION}

The University Grants Commission (UGC) of India has recently brought out a guidance document called UGC-Good Academic Research Practices or UGC-GARP (Patwardhan et al., 2020) to bring qualitative changes in conducting quality research with integrity and focus on publishing the research outcomes in high-quality journals. The primary aim or focus of the guidance document is to facilitate Indian higher education institutions, mainly universities, to establish the Office of Research Integrity or ORI to guide researchers to practice ethical standards in conducting research and disseminating or publishing research results in high-quality journals by avoiding predatory or unscrupulous journals. The effort of UGC to introduce a guidance document on academic research practices is highly laudable given the nature of Indian academics who succumb to publish their research findings in predatory journals in large numbers (Moher et al., 2017). With this guidance document and other initiatives, notably the UGC-Consortium for Academic \& Research Ethics or UGC-CARE List of Journals, the UGC, an apex body of the Indian higher education system, is bringing a sea-change in how research is being conducted and disseminated in India.

The UGC's efforts are essential in curbing the surge of predatory publishers and journals in India and promoting academic integrity through various initiatives. The UGC-Good Academic Research Practices or UGC-GARP document and UGC-CARE List seem to be very narrow in their approach. Both of them strongly support the traditional model of scholarly publications instead of looking at or exploring the rapid changes occurring in the past few years in scientific publishing world. Scholarly communication is undergoing a rapid change with new emerging open publication models (Herman et al., 2020; Hoy, 2020). It is high time for Indian academic bodies like UGC to explore new scholarly publishing models to bring concrete changes in research publications instead of relying on the traditional model of publishing, which is slow, time-consuming, and at times biased (Smith, 2006; Vlasschaert et al., 2020). More importantly, to make our scientific publication open for free access and broader dissemination of societal benefits of research results. This paper discusses how a preprint, a new open publication model, has become a significant vehicle in disseminating COVID-19 research and its role in scholarly publishing. Further, the article also argues that if open publishing (e.g., preprints and open data repositories) becomes part of the Indian scientific publishing system, how it will halt the predatory publications to a large extent. This article also urges UGC to include in GARP about emerging open publishing platforms and their benefits and encourage researchers to publish 
and deposit their articles in preprints and other open publishing platforms and make available research data in open data repositories.

\section{PREPRINTS DURING COVID-19 PANDEMIC}

During the COVID-19 pandemic, research communication was disseminated via emerging open publication platforms such as preprints (Fraser et al., 2020). Preprints are nothing but "a version of a scientific manuscript posted on a public server before formal peer review. As soon as it is posted, your preprint becomes a permanent part of the scientific record, citable with its own unique DOI" (PLOS, 2020). In simple terms, preprints can be termed as finished drafts of scholarly work, not yet peerreviewed or free versions of official versions of peer-reviewed papers. Preprints are advantageous in rapidly disseminating research results, establishing priority over others' works, and allowing community participation in online discussion or feedback, which significantly helps in improving the manuscript. The DOI associated with the manuscript attracts early citations. Studies have reported that manuscripts deposited in preprint servers receive more citations than published through traditional scholarly journals (Davis \& Fromerth, 2007; Fraser et al., 2019). Figure 1 indicates the top 10 COVID-10 publication platforms, citation counts and means citations for these publications. This trend shows that articles deposited prior publications as preprints receive early citations and how preprint servers have emerged as significant publication channels for publishing or depositing research articles.

arXiv, one of the first preprint servers to be started in high energy physics in 1991, has been running successfully and has become an important platform for physicists, mathematicians and computer scientists to post or deposit their articles before formal publications. Since then, preprint repositories and the disciplines they serve have expanded significantly. Leading preprint servers now include SocArXiv in the social sciences, bioRxiv in biology, EngrXiv in engineering, ChemRxiv in chemistry, PsyArXiv in psychological sciences, LawArXiv in legal scholarship, EarthArXiv in Earth science fields, and medRxiv in health sciences (Balaji \& Dhanamjaya, 2019; Puebla et al., 2021). agriRxiv in agriculture and allied sciences started in 2017 by Open Access India, an advocacy group supporting the open access movement in India that has been attracting the attention of agricultural scientists in India to make their research public through preprints. Most of the preprint servers named above are running by non-profit organizations. For instance, bioRxiv and medRxiv were launched in the year 2013 and 2019, respectively, by Cold Spring Harbor Laboratory, a not-for-profit research and 
educational institution. Now both the preprint servers are supported by Chan Zuckerberg Initiative. There are few preprint servers run by commercial players as well. Notable examples are SSRN by Elsevier Inc., Research Square, MDPI preprints, and PeerJ. Currently, around 55 preprint servers are operating in the different subject domains.

\begin{tabular}{|c|c|c|c|}
\hline Publication Platforms & Publications $v$ & Citations & Citations mean \\
\hline medRxiv & 10,210 & 60,899 & 5.96 \\
\hline SSRN Electronic Journal & 7,969 & 12,573 & 1.58 \\
\hline Research Square & 7,912 & 2,965 & 0.37 \\
\hline bioRxiv & 3,994 & 25,160 & 6.30 \\
\hline arXiv & 3,386 & 218 & $\mid 0.06$ \\
\hline The BMJ & 2,010 & 19,908 & 9.90 \\
\hline Science & 1,701 & 26,514 & 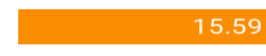 \\
\hline JMIR Preprints & 1,633 & | 375 & $\mid 0.23$ \\
\hline $\begin{array}{l}\text { International Journal of } \\
\text { Environmental Research } \\
\text { and Public Health }\end{array}$ & 1,465 & 8,369 & 5.71 \\
\hline Sustainability & 1,423 & | 2,055 & 1.44 \\
\hline
\end{tabular}

Fig. 1. COVID-19 publications in Preprints and other Publishing Platforms ((As on $11^{\text {th }}$ February 2021)

Many open-access journal publishers, including eLife and the Public Library of Science (PLOS), have mandated depositing manuscripts in a preprint server before prior publications in their journals. Nature and Science have been accepting preprints for a long time (Balaji \& Dhanamjaya, 2019). Now bioRxiv and medRxiv allow authors to directly transfer their articles to as many as 120 journals in a single click. These features speed up the submission process of articles and save much time for authors. The open review system or comments or community feedback or community inputs available in preprint servers for deposited articles add value or provide additional information for reviewers to evaluate articles more quickly and transparently.

There is a concern that low-quality articles would be flooded in preprints because of lack of peer review process, but over the years, it has been proved wrong, and the study done by Abdill \& 
Blekhman (2019) shows that almost 67\% of the articles deposited in bioRxiv preprints have subsequently published in peer-reviewed journals. Preprints also support for rapid evaluation of controversial results. The paper "Uncanny similarity of unique inserts in the 2019-nCoV spike protein to HIV1 gp120 and Gag" claimed to have found similarities between the new coronavirus and HIV, the virus that causes AIDS, deposited in bioRxiv on $31^{\text {st }}$ January 2020, but was immediately withdrawn within a day or two after widespread criticisms and comments it received on the preprint server and social media platforms such as Twitter. It would have taken years to correct or withdraw the article in formal peer-reviewed journals (Oransky \& Marcus, 2020). On the other hand, peer-reviewed journals also have issues with their article vetting process. For example, during the COVID-19 pandemic, the highly regarded peer-reviewed medical science journals New England Journal of Medicine (NEJM) and The Lancet had to withdraw the articles that they had published on "Cardiovascular Disease, Drug Therapy, and Mortality in Covid-19" and "Hydroxychloroquine or chloroquine with or without a macrolide for treatment of COVID-19: a multinational registry analysis" for lacking substantial data to back up their studies (Althouse, 2020). So peer-reviewed journals have also had issues with their own vetting process, but it's not only preprints. Preprints are quick to update their websites with a cautionary note that preprints are preliminary reports of work that have not been certified by peer review.

\section{PREPRINTS AND OPEN DATA REPOSITORIES FOR CURBING PREDATORY PUBLICATIONS}

The interest of Indian authors in depositing articles in preprints is not encouraged much (Singh et al., 2020). There is a need to encourage or mandate authors to deposit their manuscripts in preprint servers before submitting them to journals for formal publications. Preprints will not only make publications openly accessible but also vastly reduce predatory publications. One of the reasons for escalating predatory publications in India was the most of the research publications were not made their research data (survey data, experimental data, simulations, software, codes, stastical methods/data, etc) available for validation or reproducibility of research. Preprint servers supports depositing associated research data or supplementary data along with the manuscripts. Hence, research reproducibility and the assessment of scientific validity of preprints can be done quickly and easily. The pre-publication peer-review or open peer-review (even through comments) of preprints can also halt the predatory publications to an extent. 
The UGC-CARE's website lists 1157 journals in different subject domains published in India (see Figure 2), which is not enough to cater to the needs of the growing Indian scientific community. According to the AISHE survey of 2018-19, as many as 169170 students pursued their PhDs in various Indian universities. If we compare the number of journals listed in the UGC-CARE List and the number of students pursuing their research career, there is no match. If we include both $\mathrm{PhD}$ and M.Phil. researchers studying in India together, the number of research students exceed 199862, that is almost 2 lakh researchers (See Figure 3). This number includes only $\mathrm{PhD}$ and M.Phil research students, and if we include faculty of India Universities and researchers in various research institutions, including CSIR Labs, IITs and other research institutions, the numbers will be huge. There is a mismatch between number of journals or publication avenues and number of researchers persuing research in our country. The UGC and other higher educational apex bodies should encourage learned societies and research institutions to bringout or publish scholarly journals. Posting preprints have multiple benefits for early career researchers (ECRs). It helps in accelerating scientific communications, increase visibility through social media platforms and facilitate professional networking. It facilitates early access to knowledge and data. It can also save months to years of ECR research and training time, reduce costs, encourage risk-taking, and facilitate publishing research findings to a larger audience without additional funds or incurring article processing charges (APCs). Preprints offer all research findings to be made public, including harmful data or results, which is highly beneficial for ECRs (Sarabipour et al., 2019).

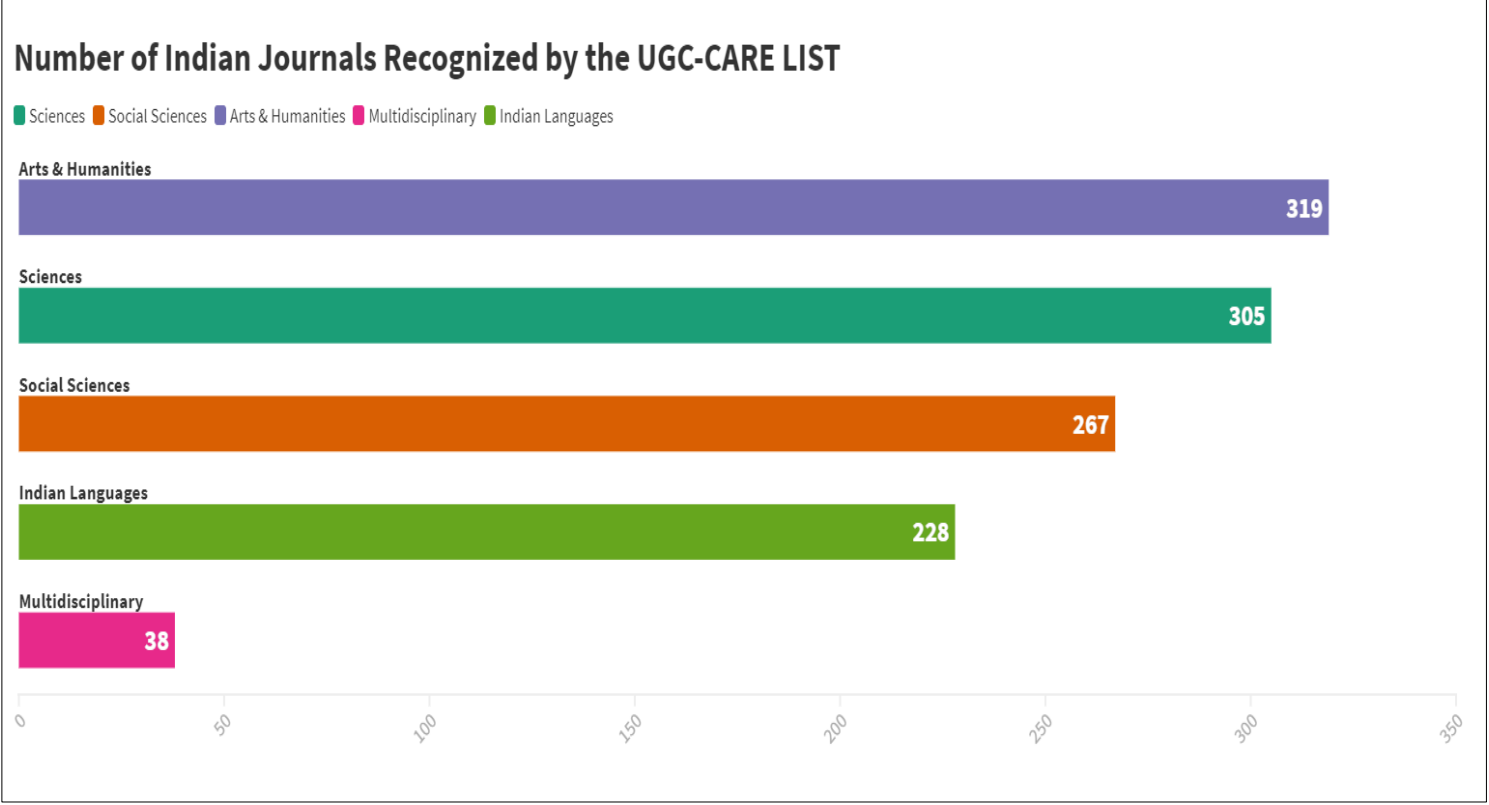

Fig. 2. Indian Journals Listed in UGC-CARE Website (As of January 2021) 
The traditional scholarly publishing industry is skewed towards western countries, mainly the US and UK. Recently, this has been eloquently argued in one of the articles authored by Berger (2021). The article also documents the efforts of the global South in disseminating or providing visibility for their research output. Some notable examples are SciELO preprints, AAS Open Research of African Academy of Science, AfricaArxiv, the REDALYC project, Indonesia's SINTA (Science \& Technology Index). There are other efforts to provide visibility for research produced in Latin America and other Global South countries, which have been well documented by Berger (2021). India should also emulate or follow similar efforts to provide more comprehensive scholarly platforms for its researcher to publish and make their research available freely through open publishing platforms mainly that have been initiated in Latin America. Because India also resembles similar language diversity. Recently, INA-Rxiv, IndiaRxiv of Open Access India, and FrenXiv language-specific preprints started between 2017 to 2019 in Indonesia, India and France, respectively have stopped accepting preprints from October 2020, the governments or non-profit organizations should have backed up these preprint servers to foster the research produced in local languages in their respective countries.

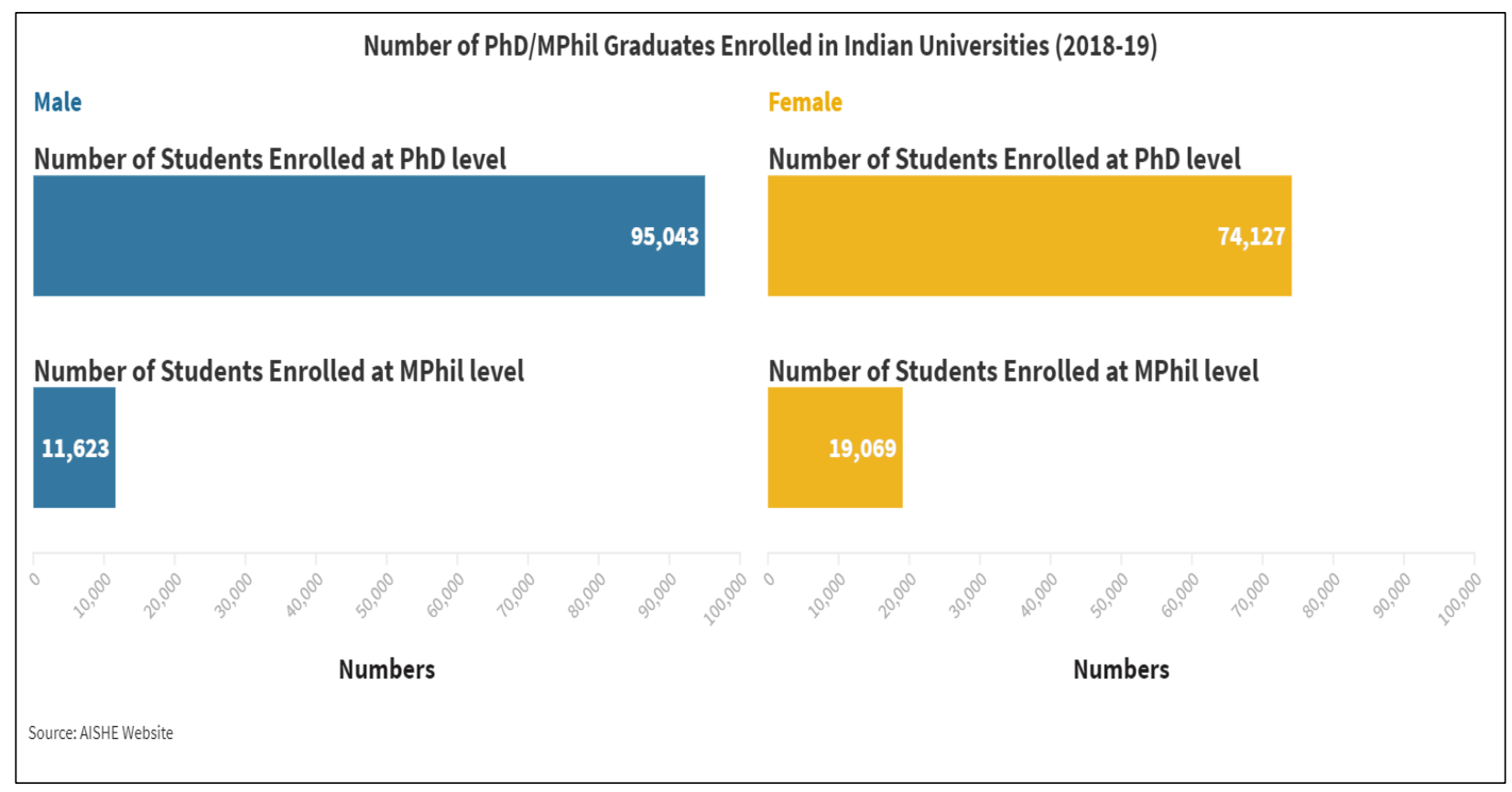

Fig. 3. Number of PhD/MPhil Students Enrolled in Indian Universities 
The policy statement of the Indian National Science Academy on "Dissemination and Evaluation of Research Output in India" in 2018 recommended for promoting preprints in India (Chaddah \& Lakhotia, 2018), but not much has been done since then. However, the Draft $5^{\text {th }}$ National Science, Technology \& Innovation Policy 2020 (Department of Science \& Technology, 2020) has also emphasized the importance of open science. It has made some important recommendations to promote open access and establishing Indian Science and Technology Archive of Research (INDSTA) to provide access, specifically, to the outputs of all publicly-funded research (including manuscripts, research data, supplementary information, research protocols, review articles, conference proceedings, monographs, book chapters, etc.). The establishment of INDSTA is an interesting move, and it should come to reality at the earliest.

The overemphasis on journal impact factor (JIF) for assessing individual researchers for funding research and career advancement scheme has drawn much criticism. The UGC-CARE List precisely relies on this aspect and promotes citation metrics as the sole criteria for evaluating researchers' performance or publications. Balaram, the former director of IISc, has been vocally criticizing using citation metrics and JIF to assess researchers' publications. He had extensively authored a few editorials in Current Science on this aspect when he was the journal editor (Balaram, 2004, 2009, 2010, 2013). The San Francisco Declaration of Research Assessment (DORA) declaration and the Leiden Manifesto for Research Metrics (Curry, 2018; Hicks et al., 2015) have been now encouraging funding agencies and universities to use qualitative or expert assessment along with a quantitative evaluation to assess the quality of research articles instead of where it was published or the impact factor of journals and citation metrics of the author (e.g., h-index). To date, 19016 individuals and organizations have signed the DORA declaration.

\section{CONCLUSION}

Preprints, open peer review, open data repositories, overlay journals, under broader umbrella of open science have been altering how scholarly communication is being communicated over the years and challenging the status quo of traditional scholarly publishing models. The UGC-CARE List and GARP have not been much engaged in ongoing developments in the scholarly publishing world. Instead, they promote age-old practices or a traditional scholarly publishing system publishing a final version of an article in peer-reviewed journals which comes under pay-wall system. The COVID-19 pandemic has exposed the limitations of paywalled scholarly content, and it was open publishing 
platforms, including preprints that thrived during this pandemic. It is the right time for the UGC to move away in a phased manner from maintaining a white list of journals or CARE List and embrace Open Science and develop open infrastructure to bring more transparency in research and increase the visibility of Indian research publications to the world.

\section{REFERENCES}

Abdill, R. J. and Blekhman, R. 2019. Meta-Research: Tracking the popularity and outcomes of all bioRxiv preprints. Elife, 8, e45133. DOI: 10.7554/eLife.45133

Althouse, A. D. 2020. How did this pass peer review? Thoughts on the Lancet and NEJM COVID19 retractions. Medscape. Retrieved from https://www.medscape.com/viewarticle/932262\#vp 1

Balaji, B. P. and Dhanamjaya, M. 2019. Preprints in scholarly communication: Re-imagining metrics and infrastructures. MDPI Publications, 7, 6.

Balaram, P. 2004. Science, scientists and scientometrics. Current Science, 86, 623-624.

Balaram, P. 2009. Metrics of science: Loosening the stranglehold. Current Science, 1289-1290.

Balaram, P. 2010. Citations, impact indices and the fabric of science. Current Science, 99, 857-858.

Balaram, P. 2013. Research assessment: declaring war on the impact factor. Current Science, 104, 12671268.

Berger, M. (2021). Bibliodiversity at the centre: Decolonizing open access. Development and Change.

Chaddah, P. R. A. V. E. E. N. and Lakhotia, S. C. 2018. A policy statement on Dissemination and Evaluation of Research output in India by the Indian National Science Academy (New Delhi). In Proc Indian Natn Sci Acad (Vol. 84, No. 2, pp. 319-329).

Curry, S. 2018. Words were a good start-now it is time for action. Nature, 554, 147-147.

Davis, P., \& Fromerth, M. (2007). Does the arXiv lead to higher citations and reduced publisher downloads for mathematics articles?. Scientometrics, 71(2), 203-215.

Fraser, N., Brierley, L., Dey, G., Polka, J. K., Pálfy, M., Nanni, F. and Coates, J. A. 2020. Preprinting the COVID-19 pandemic. BioRxiv.

Fraser, N., Momeni, F., Mayr, P. and Peters, I. 2019. The effect of bioRxiv preprints on citations and altmetrics. BioRxiv, 673665. https://doi.org/10.1101/673665

Herman, E., Akeroyd, J., Bequet, G., Nicholas, D. and Watkinson, A. 2020. The changed-and changing-landscape of serials publishing: Review of the literature on emerging models. Learned Publishing, 33, 213-229.

Hicks, D., Wouters, P., Waltman, L., De Rijcke, S. and Rafols, I. 2015. Bibliometrics: the Leiden Manifesto for research metrics. Nature News, 520, 429. 
Hoy, M. B. 2020. Rise of the Rxivs: How preprint servers are changing the publishing process. Medical Reference Services Quarterly, 39, 84-89.

Department of Science \& Technology. 2020. Draft Science, Technology \& Innovation Policy (STIP) (Doc 1.4.). Retrieved from https://dst.gov.in/sites/default/files/STIP_Doc_1.4_Dec2020.pdf

Moher, D., Shamseer, L., Cobey, K. D., Lalu, M. M., Galipeau, J., Avey, M. T. and Ziai, H. 2017. Stop this waste of people, animals and money. Nature News, 549, 23.

Oransky, I., and Marcus, A. 2020). Quick retraction of a faulty coronavirus paper was a good moment for science. STATNEWS. Retrieved from https://www.statnews.com/2020/02/03/retraction-faulty-coronavirus-paper-good-momentfor-science/

Patwardhan, B., Desai, A., Chourasia, A., Nag, S. and Bhatnagar, R. 2020. Good Academic Research Practices. University Grants Commission. Retrieved from https://www.ugc.ac.in/ebook/UGC GARP 2020 Good\%20Academic\%20Research\%20Practices.pdf

PLOS.org. (2020). Preprints. https://plos.org/open-science/preprints/

Puebla, I., Polka, J. and Rieger, O. 2021. Preprints: Their evolving role in science communication.

Sarabipour, S., Debat, H. J., Emmott, E., Burgess, S. J., Schwessinger, B. and Hensel, Z. 2019. On the value of preprints: An early career researcher perspective. PLoS Biology, 17, e3000151.

Singh, V. K., Srichandan, S. S. and Piryani, R. 2020. Preprint submissions by Indian scientists in arXiv. Current Science, 119(6), 904.

Smith, R. 2006. Peer review: A flawed process at the heart of science and journals. Journal of the Royal Society of Medicine, 99(4), 178-182.

Vlasschaert, C., Topf, J. and Hiremath, S. 2020. Proliferation of papers and preprints during the COVID-19 pandemic: Progress or problems with peer review?. Advances in Chronic Kidney Disease. 